\title{
Substratos e ácido indol-3-butírico na produção de mudas de pitaia vermelha de polpa branca ${ }^{1}$
}

\author{
Elaine Cristina Galvão $o^{2}$, José Darlan Ramos ${ }^{2}$, Leila Aparecida Salles Pio ${ }^{2}$, Ranieri Reis Laredo², \\ Fábio Oseias dos Reis Silva², João Marcos de Sousa Miranda ${ }^{2}$
}

$10.1590 / 0034-737 X 201663060016$

\section{RESUMO}

A pitaia é uma cactácea frutífera originária das florestas tropicais da América do Sul e Central. Produz frutos não convencionais muito apreciados, com grande potencial para diversificação do setor. É propagada preferencialmente por estaquia, proporcionando aumento na precocidade e uniformidade dos pomares. Com o intuito de maximizar a produção de mudas, objetivou-se avaliar diferentes concentrações de ácido indol-3-butírico (AIB) e três tipos de substratos na produção de mudas de pitaia (Hylocereus undatus). O experimento foi conduzido em delineamento experimental em

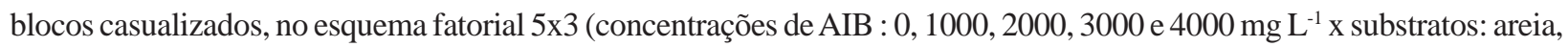
areia + solo, solo), com três repetições. Após 120 dias avaliaram-se: número e comprimento de cladódios e a biomassa fresca e seca de raízes e parte aérea. Os resultados foram submetidos à análise de variância, as médias dos substratos agrupadas pelo teste de Scott-Knott e o efeito do AIB avaliado pela análise de regressão. Verificou-se efeito significativo da interação entre doses de AIB e tipos de substratos apenas para a variável número de cladódios. A imersão das estacas em solução com AIB resultou em diferenças significativas nas características fitotécnicas: número e comprimento dos cladódios, biomassa fresca das raízes e parte aérea. A significância dos substratos ocorreu para as variáveis biomassa fresca e seca das raízes. A faixa compreendida entre 1776,33 e $2299 \mathrm{mg} \mathrm{L}^{-1}$ de AIB proporciona maior crescimento de mudas de pitaia. $\mathrm{O}$ substrato areia promove maior enraizamento das mudas.

Palavras-chave: Hylocereus undatus; propagação; estaquia; auxina.

\section{ABSTRACT}

\section{Substrates and indol butyric acid on red dragon fruit of white pulp seedlings production}

Dragon fruit is a fruitful cactus originating in the tropical rainforests of South and Central America. It produces unconventional fruits that are much appreciated, with great potential for diversification of the sector. It is propagated preferentially by cutting, providing increase in the precocity and uniformity of the orchards. In order to maximize the production of seedlings, the objective was to evaluate different concentrations of indole-3-butyric acid (IBA) and three types of substrates in the production of dragon fruit seedlings ((Hylocereus undatus). The experiment was conducted in experimental design in a completely randomized block design with factorial $5 \times 3$ (IBA concentrations: 0 , 1000, 2000, 3000, and $4000 \mathrm{mg} \mathrm{L}^{-1} \times$ substrates: sand, sand + soil, and soil) with three reapplications. After 120 days, the following characteristics were evaluated: number of lateral cladodes, length of cladodes, fresh root biomass, dry root biomass, fresh shoot biomass, and dry shoot biomass. The results of the variables were subjected to analysis of variance and the substrates were compared by Scott-Knott and the effect of the IBA was evaluated by regression.

\footnotetext{
Submetido em 23/03/2015 e aprovado em 05/08/2016.

${ }^{1}$ Este trabalho é parte da Dissertação de Mestrado da primeira autora. Fonte Financiadora: CNPq.

${ }^{2}$ Universidade Federal de Lavras, Departamento de Agricultura, Lavras, Minas Gerais, Brasil.elaineufla@msn.com; darlan@dag.ufla.br; leila.pio@dag.ufla.br; ranieri.agronomo@yahoo.com.br; foseias@yahoo.com.br; jmarcosmiranda@bol.com.br

*Autora para correspondência: elaineufla@msn.com
}

Rev. Ceres, Viçosa, v. 63, n.6, p. 860-867, nov/dez, 2016 
There was a significant effect of the interaction between IBA doses and substrate types only for the variable number of cladodes. The immersion of the cuttings in solution with IBA resulted in significant differences in the phytotechnical characteristics: number and length of the cladodes, fresh root and fresh shoot biomass. The significance of the substrates occurred for the fresh and dry biomass of the roots. The range between 1776.33 and $2299 \mathrm{mg} \mathrm{L}^{-1}$ of IBA provides greater growth of dragon fruit seedlings. The substrate sand promotes greater rooting of the seedlings.

Key words: Hylocereus undatus; propagation; cuttings; auxin.

\section{INTRODUÇÃO}

A fruticultura é um dos setores que mais se destacam no agronegócio brasileiro, gerando emprego e renda. $\mathrm{O}$ Brasil é o terceiro maior produtor de frutas do mundo, ficando atrás apenas de China e Índia, sendo responsável pela produção de 43,6 milhões de toneladas de frutas em 2013 em cerca de 2,2 milhões de hectares, tornando evidente a relevância do setor para a economia brasileira (Sebrae, 2015). Este importante ramo do agronegócio tem sido impulsionado pela maior conscientização da população, que busca alimentos saudáveis, nutritivos, nutracêuticos e com baixo teor calórico (Vitti et al., 2003; Goto \& Hora, 2010).

Este cenário contribui para a abertura de espaço ao consumo das mais diversas espécies frutíferas, inclusive as não convencionais. $\mathrm{O}$ despertar do interesse por esse tipo de fruta é decorrente do sabor diferenciado e do conteúdo de minerais, fibras e componentes antioxidantes. Dentre as diversas opções de espécies frutíferas não convencionais, com perspectivas promissoras de mercado, destaca-se a pitaia (Hylocereus undatus), uma cactácea nativa das florestas tropicais da América Central e do Sul, Índia e Malásia (Canto, 1993; Nerd \& Mizrahi, 1998).

$\mathrm{O}$ aumento do consumo de pitaia pelos brasileiros tem levado produtores a aumentarem a produção, pois além do consumo in natura, a fruta pode ser processada na forma de geleias, sucos, sorvetes e doces (Donadio, 2009) e ainda tem aplicação na indústria farmacêutica e de cosméticos (Molina et al., 2009), refletindo diretamente no aumento das vendas.

A planta é perene, com hábito de crescimento epífito e com raízes adventícias que auxiliam na fixação e obtenção de nutrientes. Possui cladódios triangulares, suculentos, com pequenos espinhos. A flor é hermafrodita, de coloração branca, com antese noturna, e frutos externamente vermelhos, com polpa branca e grande número de diminutas sementes de coloração preta. Seu sabor é agradável e levemente adocicado (Donadio, 2009; Silva et al., 2011).

Dentre as espécies, duas destacam-se comercialmente: a pitaia vermelha de polpa branca e a vermelha na casca, mas com polpa também vermelha. A planta é uma cactácea, que aparentemente está se adaptando em diferentes climas e solos. A produtividade média dessa frutífera varia de 10 a $30 \mathrm{t} \mathrm{ha}^{-1}$, dependendo das condições edafoclimáticas, das técnicas de cultivo empregadas e da idade do pomar (Le Bellec et al., 2006).

Os países detentores das maiores produções são Colômbia e México. No Brasil, existem pequenas áreas produtoras, as quais estão situadas principalmente no Estado de São Paulo (Bastos et al., 2006).

A propagação da pitaia é realizada, na maioria das vezes, por estaquia, um dos métodos mais importantes de clonagem utilizados na fruticultura, pois resulta na fixação de genótipos selecionados, na uniformidade das populações, na facilidade da propagação, na antecipação do período de florescimento, na redução do período juvenil e no maior controle das fases de desenvolvimento (Franco et al., 2007). As plantas originadas iniciam o seu florescimento um ou dois anos após o plantio. Este método de propagação, utilizando cladódios inteiros ou segmentados, tem como vantagem a precocidade da produção, a praticidade e a uniformidade no seu cultivo, notadamente, dos tratos culturais (Andrade et al., 2007; Cardoso et al., 2011; Marques et al., 2012).

Dois fatores são importantes para o enraizamento de estacas de pitaia: os tipos de substratos e as auxinas.

A escolha do substrato ideal deve ser feita em função da espécie a ser trabalhada, do tipo de estaca, da época e do custo (Le Bellec et al., 2006). Dentre os reguladores de crescimento, destacam-se as auxinas, fitorreguladores que atuam diretamente na formação de raízes adventícias, na ativação das células do câmbio e promovem o crescimento das plantas (Taiz \& Zeiger, 2013).

Dentro do grupo das auxinas, um dos reguladores de crescimento utilizado até o momento é o ácido indol-3butírico (AIB), que apresenta como principal função estimular a iniciação radicial, promovendo o aumento na percentagem de raízes, atuando na uniformidade do enraizamento e possibilitando a redução do tempo de permanência das estacas na fase de produção de mudas de várias espécies vegetais (Fachinello et al., 2005; Dutra et al., 2012; Smarsi et al., 2008). 
A pitaia, por se tratar de uma espécie ainda pouco explorada nas áreas agrícolas brasileiras, demanda maiores informações técnicas sobre a sua propagação, demandando novas pesquisas.

Assim, visando a ampliar o conhecimento com relação à propagação da pitaia, objetivou-se com este trabalho, avaliar diferentes concentrações de ácido indol-3-butírico e de três tipos de substratos na produção de mudas dessa espécie.

\section{MATERIAL E MÉTODOS}

O experimento foi conduzido de agosto a dezembro de 2013, no Departamento de Agricultura (DAG), no Setor de Fruticultura da Universidade Federal de Lavras (UFLA), em Lavras, Minas Gerais (MG). O município de Lavras situa-se a $21^{\circ} 14^{\prime} 06^{\prime \prime} \mathrm{S}$ e 4500'00" O e altitude média de 918 metros (Sebrae, 1998). De acordo com a classificação climática de Köppen, modificada por Dantas et al. (2007), o clima da região é do tipo Cwa, temperado chuvoso (mesotérmico), caracterizado por apresentar inverno seco e verão chuvoso.

O delineamento experimental utilizado foi o de blocos casualizados, em esquema fatorial $5 \times 3$, com três repetições e sete plantas por parcela. O primeiro fator correspondeu às concentrações de ácido indol-3-butírico (AIB) $\left(0,1000,2000,3000\right.$ e $\left.4000 \mathrm{mg} \mathrm{L}^{-1}\right)$ e, o segundo, aos tipos de substratos (areia, areia + solo, solo), sendo a areia de textura média e o solo argiloso.

As estacas (cladódios), utilizadas para a propagação vegetativa, foram coletadas com comprimento de $25 \mathrm{~cm}$, de plantas matrizes sadias, com seis anos de idade, cultivadas no Setor de Fruticultura da UFLA, em espaçamento de $3 \times 3 \mathrm{~m}$, sustentadas sobre mourões de eucalipto a 1,8 m do solo.

O material foi lavado em água corrente e colocado para secar em temperatura ambiente $\left(25^{\circ} \mathrm{C}\right.$ e $70 \%$ de UR), durante 60 minutos. Em seguida, procedeu-se a um corte transversal na região de inserção das estacas, para possibilitar a melhor exposição do tecido interno à solução da auxina exógena. Após o corte, foi aplicada a solução de AIB, por imersão dos cladódios, durante aproximadamente 60 segundos, em recipientes que já continham as respectivas concentrações. Os cladódios com ausência de AIB foram simultaneamente imersos em água destilada e mantidos dessa forma, pelo mesmo período de tempo dos outros tratamentos.

As estacas foram plantadas em sacos plásticos de polietileno com dimensões de $30 \times 15 \mathrm{~cm}$, capacidade de aproximadamente 3,5 L, preenchidos com os seguintes substratos: areia, areia + solo (na proporção de 1:1 v/v) e solo. Foi feita análise química e física dos substratos utilizados no experimento, antes da implantação. A irrigação foi realizada de forma manual, com regador, três vezes por semana. Para cada irrigação, foram gastos de 20 a 30 litros de água, no total, aproximadamente, de 0,45 L a 0,67 L por muda.

O experimento foi conduzido sob sombrite confeccionado em polietileno, de coloração preta, que retém $50 \%$ de luminosidade, o qual foi sustentado por colunas de cimento, em uma estrutura de alvenaria com dimensões de 8 x 8 $\mathrm{m}$, totalizando $64 \mathrm{~m}^{2}$ de área.

Aos 120 dias após o plantio das estacas, foram avaliadas as seguintes características: número de cladódios laterais (NCL), determinado pela contagem; comprimento dos cladódios (CC), medido com trena milimetrada, no sentido longitudinal de cada cladódio, a partir da região de inserção à extremidade terminal; biomassa fresca (BFR) e seca das raízes (BSR), medidas pela pesagem, em balança de precisão, das raízes recém-coletadas (frescas) e após secagem em estufa de ar forçado $\left(72^{\circ} \mathrm{C}\right)$, durante 72 horas; biomassa fresca (BFPA) e seca da parte aérea (BSPA) medida pela pesagem, em balança de precisão, dos cladódios laterais recém-coletados (frescos) e secagem em estufa de ar forçado $\left(72^{\circ} \mathrm{C}\right)$, durante 72 horas.

Os resultados das variáveis foram submetidos à análise de variância, com o intuito de avaliar o efeito principal de cada um dos fatores e da interação entre eles. As médias dos substratos foram agrupadas pelo teste de ScottKnott, a 5\% de probabilidade e o efeito do AIB foi avaliado mediante análise de regressão, com o software Sisvar (Ferreira, 2011). Para a interação significativa, fez-se o desdobramento das médias.

\section{RESULTADOS E DISCUSSÃO}

Houve interação significativa entre as concentrações de ácido indol-3-butírico (AIB) e tipos de substrato, apenas para a variável número de cladódios laterais $(\mathrm{p}<0,05)$. A imersão das estacas em solução com AIB resultou em diferenças significativas nas seguintes características: número de cladódios laterais, comprimento dos cladódios e biomassa fresca da parte aérea e das raízes. Verificou-se efeito significativo dos substratos apenas para as variáveis biomassas fresca e seca das raízes.

Analisando-se o desdobramento de concentrações de AIB, dentro de cada substrato, para a variável número de cladódios laterais, observou-se que somente para o substrato areia, houve efeito significativo. Para os demais substratos, não houve efeito da concentração de AIB no aumento do número de cladódios laterais.

Considerando-se, ainda, este desdobramento (Figura 1), observou-se que, à medida que se aumentam as concentrações de AIB, ocorreu um decréscimo linear do número de cladódios laterais, quando se utilizou o substrato areia. Para os demais, não houve efeito do AIB, com média 
de 1,06 cladódios laterais para o substrato areia + solo e de 1,10 para solo, sendo que, para o substrato areia e a concentração $0 \mathrm{mg} \mathrm{L}^{-1}$, ou seja, sem utilização de AIB, o resultado foi de 1,5 cladódios laterais.

Normalmente, plantas bem supridas de substâncias de reserva brotam melhor do que aquelas debilitadas e sofrem menos com as oscilações climáticas (Nachitgal \& Roberto, 2005). Neste trabalho, o maior número de brotações em estacas plantadas no substrato areia devese a suas características favoráveis, como aeração, estrutura e baixa capacidade de retenção de água, associadas à utilização de material vegetativo (cladódios) com adequado vigor.

Já no trabalho realizado por Cajazeira \& Corrêa (2014), o número de cladódios laterais variou de 1,50 a 3,75. As plantas de pitaia apresentaram maior incremento do número de emissões laterais, até a concentração de $3000 \mathrm{mg} \mathrm{L}^{-1}$ de AIB, sendo que, quando foi utilizada uma concentração maior (4500 $\mathrm{mg} \mathrm{L}^{-1} \mathrm{de} \mathrm{AIB}$ ), houve redução tanto do número de brotações quanto do enraizamento.

Para a variável comprimento dos cladódios, a concentração de 1776,33 $\mathrm{mg} \mathrm{L}^{-1}$ de AIB proporciona o maior comprimento, com o valor aproximado de $43,90 \mathrm{~cm}$ (Figura 2).

O comprimento das estacas (cladódios) pode influenciar tanto o volume das auxinas endógenas como suas reservas de carboidratos, influenciando positivamente a taxa de sobrevivência, a emissão rápida de raízes e o número e tamanho das brotações produzidas durante seu crescimento inicial (Lima, 2013).

Segundo Botelho et al. (2005), de acordo com a concentração e o tempo de exposição, a auxina tem o potencial de inibir ou de estimular o crescimento e a posterior diferenciação dos tecidos, havendo um nível ótimo para estas respostas fisiológicas. Para Taiz \& Zeiger (2013), a concentração ótima e a inibição, são, em geral, atribuídas à biossíntese do etileno induzida pela auxina.
Para a formação de pomares uniformes, deve-se fazer uso de mudas obtidas por enraizamento de estacas, o que permite comprimentos uniformes do cladódio e favorece o desenvolvimento do sistema radicular e das brotações, embora essa resposta possa variar muito de acordo com a espécie estudada (Costa et al., 2007).

Os tipos de substratos utilizados não influenciaram o comprimento dos cladódios $(\mathrm{p}<0,05)$.

Esses dados contrariam os expostos por Silva et al. (2006), que observaram que o substrato composto por mistura de solo, areia e esterco de curral é o mais indicado para a formação de mudas de pitaia vermelha, pois, com seu uso, foram obtidas estacas com melhor enraizamento e, consequentemente, melhor desenvolvimento dos cladódios.

À medida que se aumentou a concentração de AIB, verificou-se um incremento quadrático da biomassa fresca da parte aérea, atingindo o valor máximo estimado de 109,90 g, na concentração de $2299 \mathrm{mg} \mathrm{L}^{-1}$ de AIB (Figura 3).

Resultados semelhantes foram encontrados por Cajazeira \& Corrêa (2014), em cujo trabalho a biomassa fresca da parte aérea variou de 19,21 a 71,09 g, nas concentrações de 0 e $4500 \mathrm{mg} \mathrm{L}^{-1}$ de AIB, com o melhor resultado obtido na concentração de $4500 \mathrm{mg} \mathrm{L}^{-1}$, resultando em 71,09 $\mathrm{g}$ de biomassa fresca da parte aérea.

Não houve efeito significativo dos substratos sobre a variável biomassa fresca da parte aérea (Tabela 1). Os resultados deste trabalho discordam dos encontrados por Zietemann \& Roberto (2007), para mudas de goiabeira cultivadas no substrato solo, nos quais a variável biomassa fresca da parte aérea mostrou-se inferior às dos demais substratos utilizados, sendo eles areia, areia + esterco e solo + esterco.

Conforme apresentado na Figura 4, à medida que se aumenta as concentrações de AIB, em mg L $\mathrm{m}^{-1}$, ocorre um crescimento quadrático da biomassa fresca das raízes $(\mathrm{g})$.

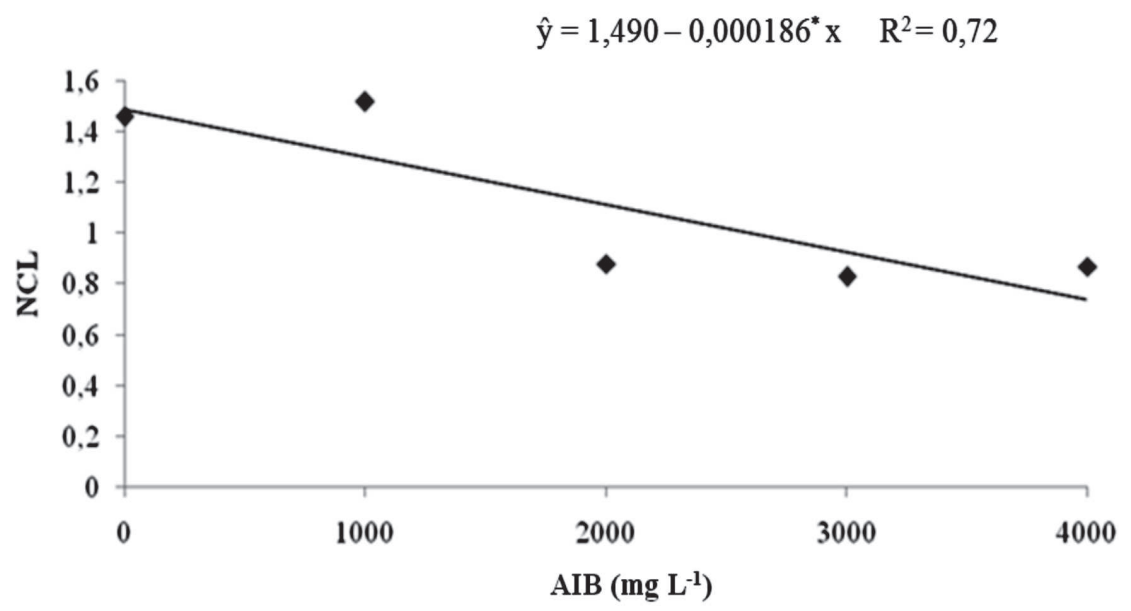

Figura 1: Número de cladódios laterais (NCL) em função da concentração de AIB no substrato areia. 
Na concentração de $2197 \mathrm{mg} \mathrm{L}^{-1}$ de AIB, ocorre o maior valor de biomassa fresca das raízes $(35,53 \mathrm{~g})$.

Estes resultados contrariam as respostas obtidas por Santos et al. (2010), que não detectaram efeito significativo da aplicação de auxina exógena (ácido indolacético) na biomassa fresca de raízes de pitaia.

Já Marques et al. (2011, 2012) observaram em estudos de propagação de pitaia vermelha, a não utilização de regulador de crescimento e proporcionaram bons níveis de enraizamento e de desenvolvimento das estacas.

No entanto, diversos autores recomendam o uso de auxinas exógenas em estacas, com o intuito de promover ou melhorar o enraizamento (Fachinello et al., 2005; Smarsi et al., 2008; Santos et al., 2010; Dutra et al., 2012).

Neste trabalho, as estacas possivelmente continham níveis endógenos de auxinas baixos, a ponto de não suprir suas necessidades para a formação de raízes, necessitando de aplicação exógena dessa substância, para estimular o desenvolvimento radicular inicial e o crescimento da estaca.

Segundo Vargas-Santiago et al. (2003), que trabalharam com Hylocereus undatus, a utilização de AIB, na concentração de $10000 \mathrm{mg} \mathrm{L}^{-1}$ antes do plantio, proporcionou, com certa rapidez, o aumento da formação de raízes adventícias.

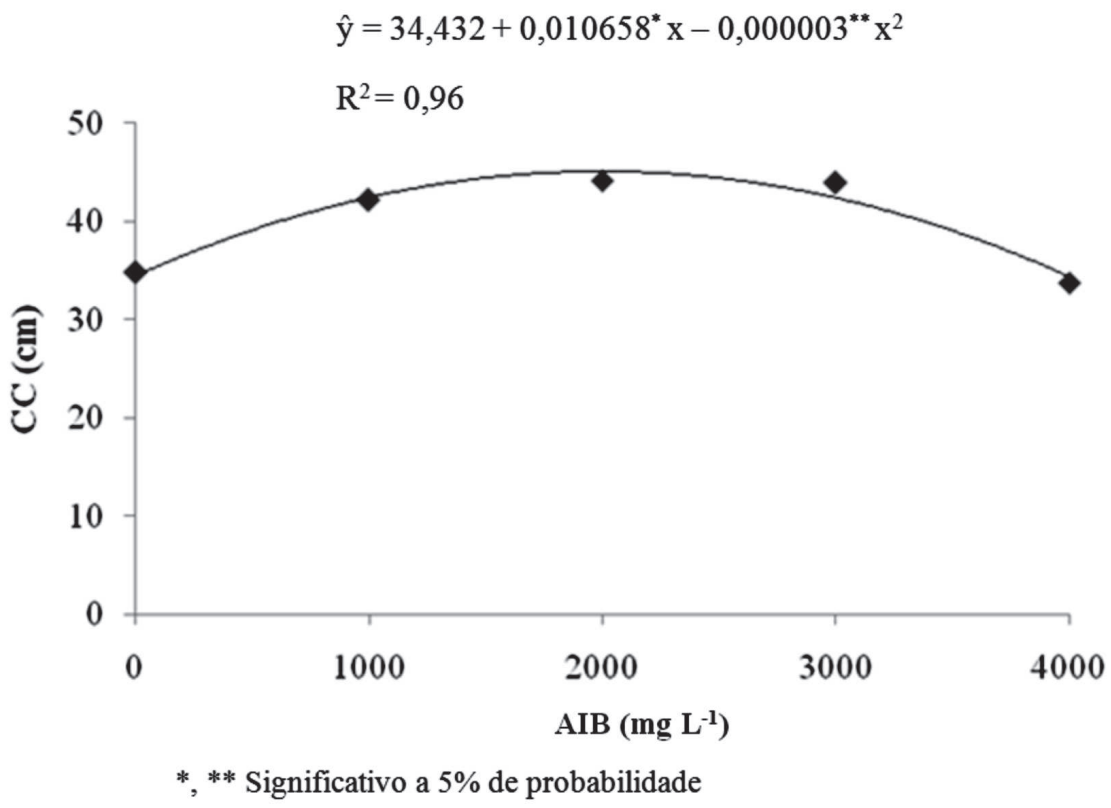

Figura 2: Comprimento dos cladódios (CC) (cm) em função da concentração de AIB no substrato areia.

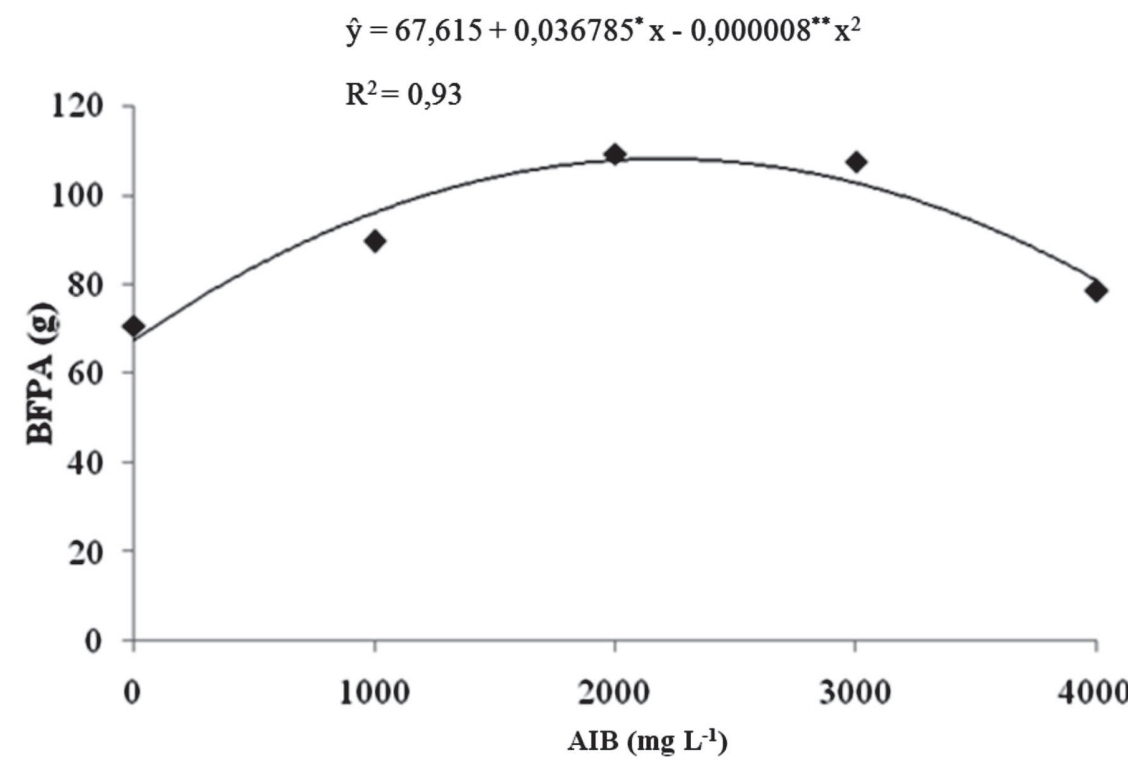

Figura 3: Biomassa fresca da parte aérea (BFPA) (g) em função da concentração de AIB no substrato areia. 
De maneira geral, em todos os tratamentos, houve grande enraizamento, que ocorreu, possivelmente, por causa da relação $\mathrm{C} / \mathrm{N}$ e do balanço hormonal de auxinas endógenas adequados para o processo de formação de raízes, conforme observado por Marques et al. (2011) e Cajazeira \& Corrêa, em 2014.

Analisando-se a variável biomassa fresca das raízes, em relação ao substrato utilizado, observou-se que os resultados mais satisfatórios foram obtidos quando se utilizaram areia e areia + solo (Tabela 1).

A maior biomassa fresca das raízes, presente nos substratos areia ou areia + solo, é desejável na formação de mudas, pois as raízes têm a função de explorar maior área, absorver água e sais minerais presentes no substrato, adaptando-se melhor quando forem transplantadas para o campo.

Nos tratamentos com solo como substrato, a variável analisada mostrou resultados inferiores ao dos substratos com a composição de areia. Esse desempenho superior dos substratos com areia, em comparação com do substrato com solo, pode ser devido à maior adaptação e à ocorrência da espécie estudada em locais com solos mais arenosos.

Estes resultados confirmam os obtidos por Silva et al. (2006), os quais concluíram que os substratos areia, solo: areia:esterco de curral curtido, fibra de coco e substrato comercial influenciaram na biomassa fresca das raízes de pitaia vermelha, sendo o substrato composto por mistura de solo, areia e esterco de curral, o mais adequado para a formação de mudas dessa frutífera.

Gunasena et al. (2007) afirmam que a pitaia adapta-se melhor em solos bem drenados, com acidez leve e com considerável teor de matéria orgânica.

O substrato mais propício deverá ter as características físico-químicas mais adequadas, para favorável crescimento e desenvolvimento radicular dos cladódios, além de ser de fácil disponibilidade e de baixo custo (Santos et al., 2010).

Em relação à variável biomassa seca das raízes (Tabela 1), houve efeito significativo para o substrato areia.

A biomassa seca das raízes ( $\mathrm{g}$ ) foi constante nas diferentes concentrações de AIB, com média de 15,10 g. Estes dados diferem dos encontrados por Cajazeira \& Corrêa (2014), que obtiveram o valor da biomassa seca das raízes variando de 2,65 a 7,13 g, nas respectivas concentrações de AIB, 4500 e $3000 \mathrm{mg} \mathrm{L}^{-1}$.

Considerando-se ainda o trabalho acima citado, a imersão dos cladódios em solução de $3000 \mathrm{mg} \mathrm{L}^{-1}$ de AIB, proporcionou a média mais expressiva de biomassa seca

Tabela 1: Médias para as características comprimento dos cladódios (CC), biomassa fresca da parte aérea (BFPA), biomassa fresca das raízes (BFR), biomassa seca das raízes (BSR), biomassa seca da parte aérea (BSPA) de mudas de pitaia vermelha

\begin{tabular}{lcrrrr}
\hline Substratos & CC $(\mathbf{c m})$ & BFPA $(\mathbf{g})$ & BFR $(\mathbf{g})$ & BSR $(\mathbf{g})$ & BSPA $(\mathbf{g})$ \\
\hline Areia & $37,91 \mathrm{a}^{*}$ & $78,06 \mathrm{a}$ & $36,22 \mathrm{a}$ & $18,85 \mathrm{a}$ & $8,68 \mathrm{a}$ \\
Solo & $40,91 \mathrm{a}$ & $93,05 \mathrm{a}$ & $28,44 \mathrm{~b}$ & $12,49 \mathrm{~b}$ & $9,12 \mathrm{a}$ \\
Areia + Solo & $40,38 \mathrm{a}$ & $101,95 \mathrm{a}$ & $32,76 \mathrm{a}$ & $13,98 \mathrm{~b}$ & $10,50 \mathrm{a}$ \\
\hline
\end{tabular}

"Grupos de médias seguidas por letras diferentes diferem estatisticamente de outros grupos pelo teste de Scott-Knott, a 5\% de probabilidade.

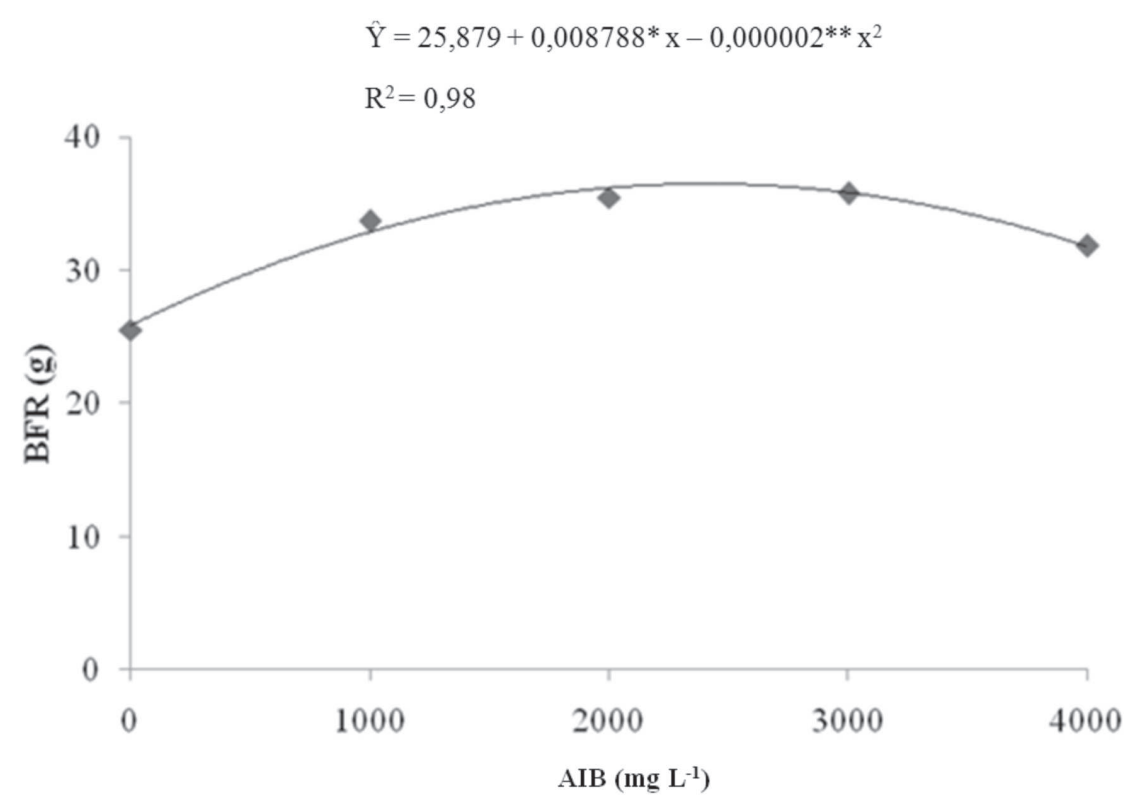

Figura 4: Biomassa fresca das raízes (BFR) (g), em função da concentração de AIB no substrato areia. 
das raízes $(7,13 \mathrm{~g})$, aproximadamente duas vezes maior que as médias das plantas que não foram imersas em AIB. Isso resulta do efeito positivo da aplicação de AIB sobre o enraizamento da pitaia, quando utilizada na concentração e com o tipo de cladódio adequado.

Estudo, realizado por Vargas-Santiago et al. (2003), resultou em resposta, bastante satisfatória, no crescimento inicial de mudas de pitaia, quando se aplicou a concentração de $10000 \mathrm{mg} \mathrm{L}^{-1}$ de AIB, bem mais alta do que as respostas significativas que foram apresentadas neste estudo. Portanto, os resultados deste trabalho são considerados promissores, visando à economia na produção de mudas.

O substrato areia proporcionou melhores resultados para a variável biomassa seca das raízes (g), conforme apresentado na Tabela 1. Esse resultado assemelha-se, em parte, aos encontrados por Silva et al. (2006), que verificaram que a mistura de solo, areia e esterco favorece a qualidade das mudas de pitaia.

Para a variável biomassa seca da parte aérea não houve efeito significativo para nenhum dos fatores estudados ou para suas interações. Isto mostra que, independentemente da concentração de AIB aplicada, o valor da biomassa seca da parte aérea $(\mathrm{g})$ foi constante $(9,42 \mathrm{~g})$.

Esses dados contrariam os apresentados por Cajazeira \& Corrêa (2014), os quais observaram em seus trabalhos que a biomassa seca da parte aérea foi influenciada pelas concentrações de AIB, sendo que seu valor variou de 1,24 a 3,98 g, nas concentrações de 0 e $4500 \mathrm{mg} \mathrm{L}^{-1}$.

Já os resultados encontrados por Santos et al. (2010) assemelham-se aos deste trabalho, os quais não detectaram efeito significativo da aplicação da auxina exógena (ácido naftalenacético - ANA) sobre a variável de mudas de pitaia.

Em contrapartida, os resultados obtidos neste trabalho contrariam os encontrados por Thiel et al. (2012), com a biomassa seca da parte aérea foi influenciada pelo uso de diferentes substratos na cultura do Fisalis, sendo eles Plantmax, fibra de coco, areia fina e vermiculita, com os melhores resultados obtidos com a vermiculita.

Lima et al. (2010) também encontraram efeitos diferenciados dos substratos na cultura do Fisalis, assim como outros autores, com as mais variadas espécies, demonstrando que o comportamento é particular para cada espécie e que depende das características físicas e químicas de cada substrato.

\section{CONCLUSÕES}

A faixa compreendida entre 1776,3 e 2299,0 $\mathrm{mg} \mathrm{L}^{-1} \mathrm{de}$ AIB proporciona maior crescimento de mudas de pitaia vermelha.

A utilização da areia promove maior crescimento do sistema radicular das mudas de pitaia vermelha.

\section{REFERÊNCIAS}

Andrade RA, Martins ABG \& Silva MTH (2007) Influência da fonte e do tempo de cura na propagação vegetativa da pitaia vermelha (Hylocereus undatus Haw.). Revista Brasileira de Fruticultura, 29:183-186.

Bastos DC, Pio R, Filho JAS, Libardi MN, Almeida LFP de, Galuchi TPD \& Bakker ST (2006) Propagação da Pitaya 'Vermelha' por estaquia. Ciência e Agrotecnologia, 30:1106-1109.

Botelho RV, Maia AJ, Pires EJP, Terra MM \& Schuck (2005) Efeitos de reguladores vegetais na propagação vegetativa do porta-enxerto de videira "43-43" (Vitis vinífera x Vitis rotundifolia). Revista Brasileira Fruticultura, 27:06-08.

Cajazeira JP \& Corrêa MC de M (2014) Comprimento de estacas e concentrações de ácido indolbutírico (AIB) na propagação vegetativa de pitaia. Revista Ciência Agronômica, 45:788-793.

Canto AR (1993) El cultivo de pitahaya en Yucatán. $1^{a}$ ed. Yucatán, Universidad Autónoma de Chapingo. 53p.

Cardoso C, Yamamoto LY, Preti EA, Assis AM de, Neves CSVJ \& Roberto SR (2011) AIB e substratos no enraizamento de estacas de pessegueiro 'Okinawa' coletadas no outono. Semina - Ciências Agrárias, 32:1307-1314.

Costa LC do B, Pinto JEBP \& Bertolucci SKV (2007) Comprimento da estaca e tipo de substrato na propagação vegetativa de atroveran. Ciência Rural, 37:1157-1160.

Dantas AAA, Carvalho LG de \& Ferreira E (2007) Classificação e tendências climáticas em Lavras, MG. Ciência e Agrotecnologia, 31:1862-1866.

Donadio LC (2009) Pitaya. Revista Brasileira de Fruticultura, 31:637-929.

Dutra TR, Grazziotti PH, Santana RC \& Massad MD (2012) Desenvolvimento inicial de mudas de copaíba sob diferentes níveis de sombreamento e substratos. Revista Ciência Agronômica, 43:321-329.

Fachinello JC, Hoffmann A, Nachtgal JC \& Kersten E (2005) Propagação vegetativa por estaquia. In: Fachinello JC, Hoffmann A \& Nachtgal JC (Eds.) Propagação de plantas frutíferas. Brasília, Embrapa. p. 69-109.

Ferreira DF (2011) Sisvar: a computer statistical analysis system. Ciência e Agrotecnologia, 35:1039-1042.

Franco D, Oliveira IV de M, Cavalcante IHL, Cerri PE \& Martins ABG (2007) Estaquia como processo de clonagem do Bacuri (Redhia garderiana Miers ex Planch e Triana). Revista Brasileira de Fruticultura, 29:176-178.

Goto R \& Hora RC (2010) Reflexões sobre a cadeia de frutas e hortaliças. In: Anuário da Agricultura Brasileira (Ed.) São Paulo, FNP Consultoria e agroinformação. p.345-347.

Gunasena HPM, Pushpakumara DKNG \& Kariyawasam M (2007) Dragon fruit (Hylocereus undatus (Haw.) Britton and Rose). In: Pushpakumara DKNG, Gunasena HPM \& Singh VP (Eds.) Underutilized fruit trees in Sri Lanka. New Delhi, World Agroforestry Centre. p. 110-142.

Le Bellec F, Vaillant F \& Imbert E (2006) Pitahaya (Hylocereus spp.): a new crop, a market with a future. Fruits, 61:237-250.

Lima CA de (2013) Caracterização, propagação e melhoramento genético de pitaya comercial e nativa do cerrado. Tese de Doutorado. Universidade de Brasília, Brasília. 124p.

Lima CSM, Severo J, Manica-Berto R, Silva JA, Rufato L \& Rufato ADR (2010) Características físico-químicas de physalis em diferentes colorações do cálice e sistemas de condução. Revista Brasileira de Fruticultura, 31:1061-1068. 
Marques VB, Moreira RA, Ramos JD, Araújo NA de \& Cruz M do CM da (2012) Porções de cladódios e substratos na produção de mudas de pitaia vermelha. Revista Agrarian, 5:193-197.

Marques VB, Moreira RA, Ramos JD, Araújo NA de \& Silva FO dos R (2011) Fenologia reprodutiva de pitaia vermelha no município de Lavras, MG. Ciência Rural, 41:984-987.

Molina DJ, Cruz JSV \& Quinto CDV (2009) Producción y exportación de la pitahaya hacia el mercado europeo. Monografia. Facultad de Economia y Negocios, Quito. 115p.

Nachitgal JC \& Roberto SR (2005) Poda e quebra de dormência. Disponível em: <http://sistemasdeproducao.cnptia.embrapa.br/ FontesHTML/Uva/MesaNorteParana/poda.htm> Acessado em: 18 de Março de 2015.

Nerd A \& Mizrahi Y (1998) Fruit development and ripening in yellow pitaya. Journal of the American Society for Horticultural Science, 123:560-562.

Santos CMG, Cerqueira RC, Fernandes LMS, Dourado FWN \& Ono EO (2010) Substratos e regulador vegetal no enraizamento de estacas de pitaya. Revista Ciência Agronômica, 41:625-629.

Sebrae (2015) Boletim de inteligência agronegócio fruticultura. Disponível em: <http://www.sebraemercados.com.br/wp-content/ uploads/2015/11/Panorama-do-mercado-de-fruticultura-noBrasil.pdf>. Acessado em: 26 de abril de 2016.

Sebrae (1998) Lavras: Diagnóstico municipal. Belo Horizonte, Serviço Brasileiro de Apoio às Micro e Pequenas Empresas. 179 p.
Silva ACC, Martins ABG \& Cavallari LL (2011) Qualidade de frutos de pitaya em função da época de polinização, da fonte de pólen e da coloração da cobertura. Revista Brasileira de Fruticultura, 33:1162-1168.

Silva MTH, Martins ABG \& Andrade RA (2006) Enraizamento de estacas de pitaya vermelha em diferentes substratos. Revista Caatinga, 19:61-64.

Smarsi RC, Chagas EA, Reis LL dos, Oliveira GF de, Mendonça V, Tropaldi L, Pio R \& Filho JAS (2008) Concentrações de ácido indolbutírico e tipos de substrato na propagação vegetativa de lichia. Revista Brasileira de Fruticultura, 30:07-11.

Taiz L \& Zeiger E (2013) Fisiologia vegetal. 5 ed. Porto Alegre, Artmed. 954 p.

Thiel FB, Gonçalves MA, Carpenedo S, Vignolo GK, Picolotto L \& Antunes LEC (2012) Desenvolvimento inicial de mudas de Physalis submetidas a diferentes substratos. In: Congresso Brasileiro de Fruticultura, Bento Gonçalves. Anais, SBF. p.32793282 .

Vargas-Santiago G, Ortiz-Hernández Y \& Alcántargonzález G (2003) Vegetative propagation of Hylocereus undatus and its relationship with substrate and IBA. Cactáceas y Suculentas Mexicanas, 48:111-117.

Vitti A, Sebastiani REG, Boteon M \& Vicentini CA (2003) Há espaço para exportar mais? Hortifruticultura Brasileira, 18:1215.

Zietemann C \& Roberto SR (2007) Produção de mudas de goiabeira (Psidium guajava L.) em diferentes substratos. Revista Brasileira de Fruticultura, 29:137-142. 